\title{
Inequality and Optimal Top Income Tax in Australia
}

\author{
Haibin $\operatorname{Lin}^{1, *}$, Chang $\operatorname{Tian}^{2}$ \\ ${ }^{I}$ School of Economics, The University of Sydney, Sydney, Australia \\ ${ }^{2}$ Business School, National University of Singapore, Singapore, Singapore \\ * Corresponding author: hlin6599@uni.sydney.edu.au
}

\begin{abstract}
Inequality is a widely discussed topic and common phenomenon all over the world. This report provides a board view of inequality in Australia, which has top rank equality among $35 \mathrm{OECD}$ countries. Although inequality has been upward trending for all over the world include Australia. For various inequality indicators, the inequality upward trends have been witnessed. Tax policy has been one of the most effective tools used by government to tackle this inequality problem, the main idea is to redistribute the wealth of the society to achieve higher utility. Different tax rates have been imposed on different income classes for the purpose, optimal labour income taxation theory by Diamond and Zaez'11 has been applied in the report to determine the theoretical optimal rate for Australia, the theoretical optimal tax rate for top $4 \%$ income class is 0.49 with a 0.5 elasticity, and theoretical rate in this report is actually higher than the actual rate, suggesting the Australia government could raise the tax rate to reduce inequality. A further step to take is investment in education system because the educational attainment is highly persistent and education is one of the key reasons for higher income.
\end{abstract}

Keywords: Economics inequality, Fiscal policy, Optimal Tax rate model, Education.

\section{INTRODUCTION}

"Economics equality can be described as an idea of "fair go": everyone is able to get ahead no matter their gender, health, ethnicity or postcode, if they work hard enough. "A high-inequality society is a highly unstable society. When assets in a society are distributed in a way that most people believe is unfair, it creates a form of systemic risk." (Leigh, 2017) [1]

Firstly, a low level-inequality society can raise social total social welfare by a good way of distributing the benefits of economics growth. Since a dollar to the poor increase utility more than that to the rich, one-dollar transfer to poor people from rich people will raise total welfare in society. There are three types of Social Welfare Functions (SWF), Rawlsian, Utilitarian and General, to formalise society's preference over redistribution, however, all these SWFs does not dependent on inequality level. Therefore, it is necessary to consider the optimal taxation to maximize total social welfare.

Secondly, economics inequality has a significantly relationships between economics opportunity and mobility. Economics mobility measures how easily one can move their position in the income distribution or wealth distribution. This mobility can be directly impacted by life-cycle and generational positions of a family. Economic opportunity will be related to things like income earning ability, chance to earn economic benefits. Economic disadvantages like poverty, although not equal to inequality, are positively related to inequality.

\section{INEQUALITY IN AUSTRALIA}

"Economic inequality is not intrinsically bad and equality does not equate to fairness." (Carling, 2017) [2], so it is hard to discuss the magnitude of economics inequality without comparing to other countries and to its history. Economics inequality could be driven by government policy, education system, and culture etcetera. To measure and understand the level of inequality in Australia, we will compare Australia's economics inequality with some OECD countries that has similar political system and history.

In this section, data for analysis and treatment of the data will be discussed in section 2.1 and 2.2, the analysis of inequality is in section 2.3, and how tax system and mobility of the economy could impact inequality will be discussed in section 2.4 . 


\subsection{Data}

In general, income, consumption and wealth represent three main forms of inequality. The three measurements are inter-related and have some transitory effects. Both wealth and consumption are measures of wellbeing, wealth can be regarded as the accumulation of past income and consumption can be view as the future expectation of income. Income is the most common measurement of the three above. Intuitively, a people with higher income can be expected to have higher wealth and consumption, although the latter two variables will also be impacted by saving rate and consumption habit. Consumption includes a utility function, which shows the preference to use their wealth and expected wealth now or in the future. Wealth is affected by not only income, but also payment-in-kind and the bequest behaviour.

Income can be directly observed from tax record, whereas the consumption and wealth data need to be collected through survey. The low-income group might not need to file a tax and high-income group might not be willing to truthfully report in the survey, so both tax record and household survey data will have their own flaws.

The gross income and disposable income are most common income type in the analysis, individually they can represent levels of inequality, and together can help observe tax system impact and some other welfare deductions. Expenditure is the proxy for consumption and net worth of asset represent wealth.

\subsection{Statistical Measurements}

Before the discussion of statistical measurements, the adjustments of data should be mentioned first. Household is another measured entity other than individuals; the variable needs to be rescaled to reflect household situation. Imputed rent is the value of housing services received from living in a rent-free dwelling, accompanied with income or wealth, it makes the data more descriptive and representative to target entity's current situation.

All the statistical measurements in this section have similar interpretation, the larger the scale of indicator, the more inequality they imply. To start with the simplest statistical measurement, people can be ranked by their income (wealth/consumption), top $\mathrm{x} \%$ of population owns y\% accumulated share of income (wealth /consumption) is the most direct observation of inequality. Then ranking percentages and descriptive ratios can be obtained, for instance, $\mathrm{P} 80 / \mathrm{P} 20$ ratio is the income share obtained by top 20th percentile population group to the bottom 20th percentile one. To draw the entire population versus income share, Lorenz curve will be obtained. Then Gini coefficient can be calculated based on the curve, it describes the curvature of Lorenz curve.

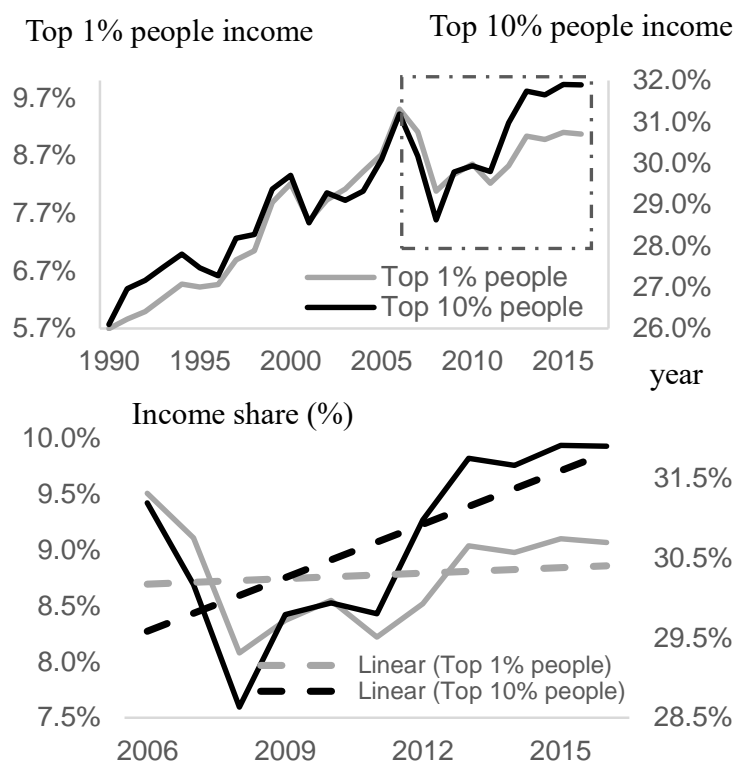

Figure 1. Different inequality trends by different measurements, different indicators showing different aspect of the income distribution

Source: The World Wealth and Income Database for years 1990-2017 as available at 8/5/2020 [3]

a. Left-hand side (LHS) graph is the top 1\% share of income and top 10\% share of income for Australia from 1990 to 2017, similar trends can be observed; right-hand side graph takes the period of 2005 to 2017 from LHS, the trend in that period is different for two indicators.

It should be noticed that different indicators and statistical measurements could lead different findings about inequality. There are many reasons for that, it could be different aspects of the distribution being measured (as represented in figure 1), different time horizons being chose (figure 1), missing data points (as represented in figure 2) etc. 
Income share (\%)
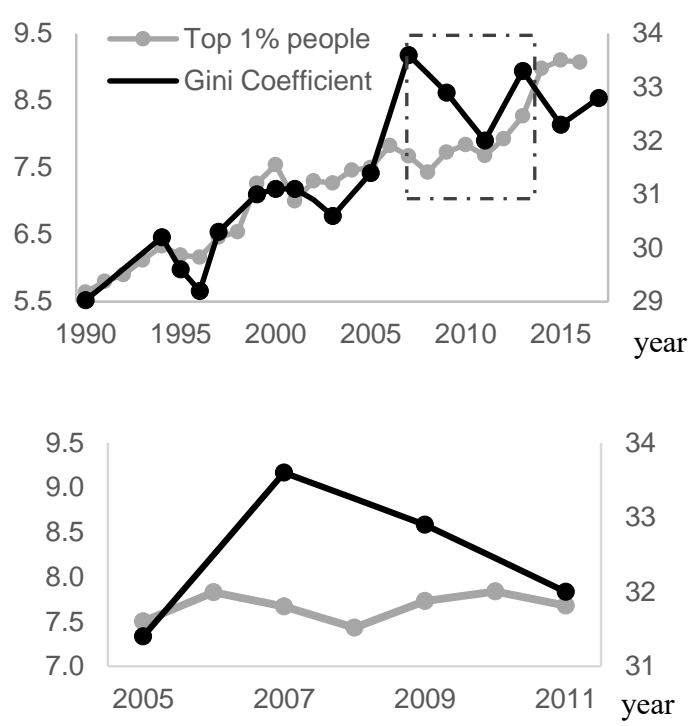

Figure 2. Different measurements may lead to different conclusion

Source:

The World Wealth and Income Database for years 1990-2017 as available at $8 / 5 / 2020$

a. Left-hand side (LHS) graph is the top 1\% share of income and top 10\% share of income for Australia from 1990 to 2017, similar trends can be observed; right-hand side graph takes the period of 2005 to 2017 from LHS, the trend in that period is different for two indicators.

Figure 2 shows very different trends by different measurements, but it might be due to lack of data points for Gini in 06, 08 and 10 years since the correlation of Gini coefficient measure and top $1 \%$ income measure should be high.

\subsection{Data Analysis}

Australia has relatively lower level of inequality compared to other countries in the world, ranked 93th out of 159 countries in the World Bank Gini index (World Bank, as cited in Index Mundi, 2020) [4]. Its ranking is slightly moving forward in the OECD country basket (Figure 3), but still in a very low level compared to some other big countries like USA and China.

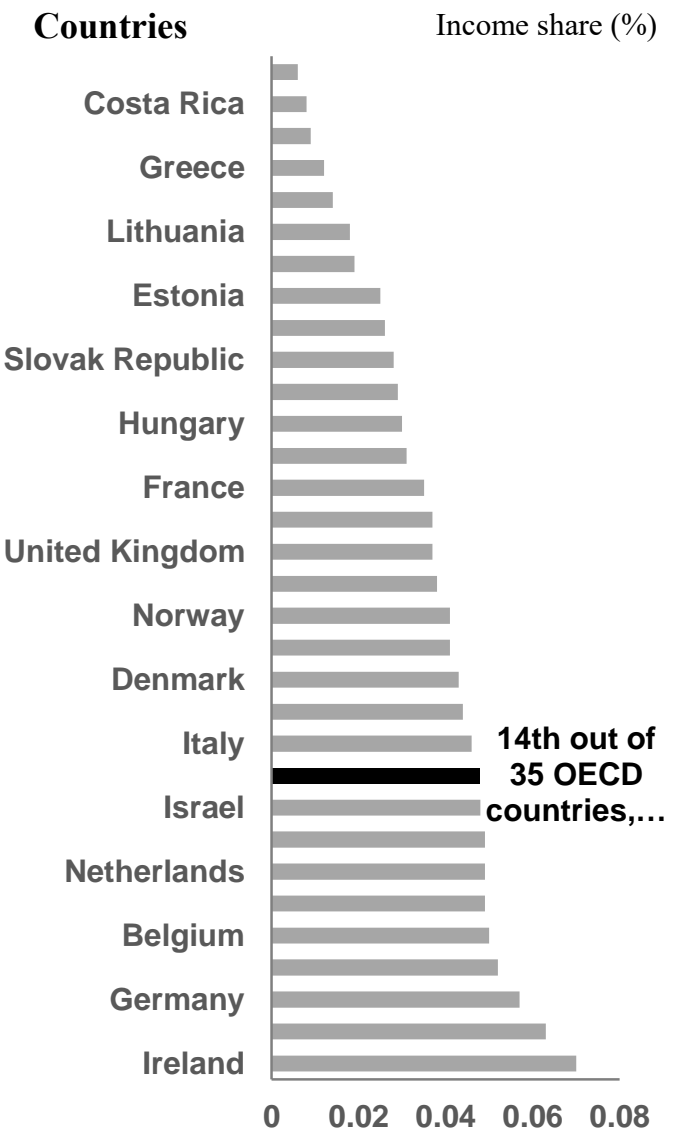

Figure 3. Tax system has effectively reduced the income inequality across country and in Australia

Source: OECD Income Distribution Database for year 2016 as available at 8/5/2020 [5];

ATO Taxation Statistics 2016-17 Table 16: Individuals [6]

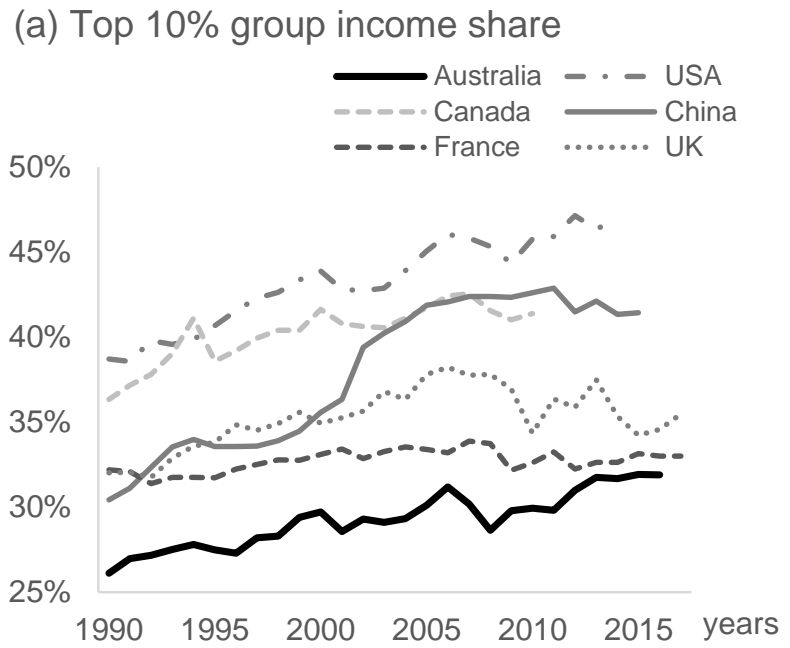




\section{(b) Top 1\% group income share}

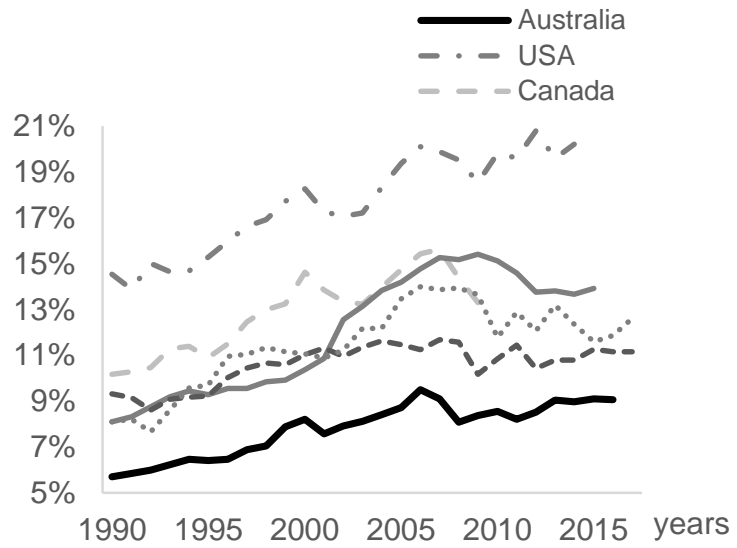

Figure 4 Australia has the lowest income inequality compared to some other big countries in the world

Source: The World Wealth and Income Database for years 1990-2017 as available at 8/5/2020

As shown in Figure 4, countries have very different level of inequality, a possible reason for that is the very different political and institutional environments for each country (Productivity Commission, 2018) [7]. Although there are fluctuations in inequality over time, all countries have upward trending in inequality as indicated by top income shares. Australia is currently in a low level of inequality, but its trending slope is steeper than UK, France and even Canada.

Over years, the income, consumption, and wealth have all grew tremendously, the consumption has been grown faster than both income and wealth. It is possible that the price level increase faster than the income level, so the consumption expenditure growing faster than income and wealth.

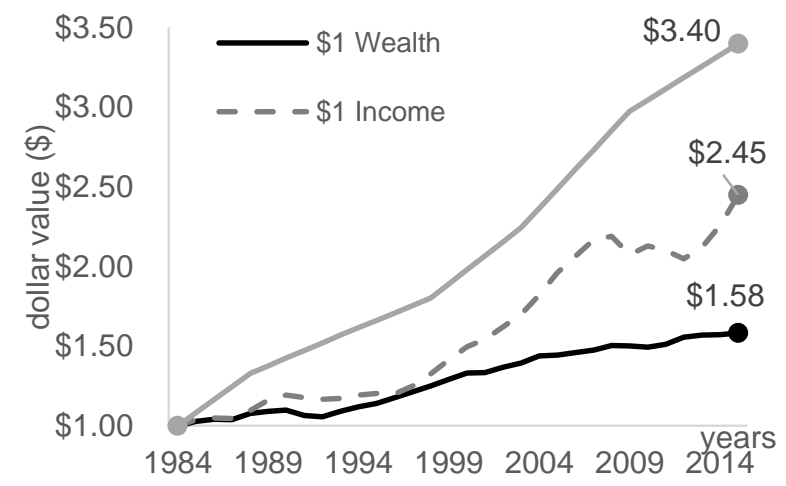

Figure 5 \$1 level in income, wealth and consumption, and its growth overtime

(a) assume income consumption and wealth are all \$1 in 1984, then they are growing at the rate compute from australia average income and average wealth of people, and surveyed household expenditure from 1984 to 2015 [8]

(b) personal average wealth will be larger than income, and average income larger than consumption, but consumption has the highest growth rate of all three measurements

Source: The World Wealth and Income Database for years 1984-2017 as available at 10/5/2020,

Australian Bureau of Statistics: Household Expenditure Survey, Australia: Summary of Results (cat. no. 6530.0). as available at 10/5/2020 [9-11]

Overall, Australia has been experiencing a rise in inequality from all measurements in this analysis. The income inequality has been increasing with online some fluctuations (Figure 6). The top 1\% income share rises from $5.5 \%$ in 1990 , heading towards $10 \%$ level until 2017. The Gini coefficient of equalized household income is showing similar trend over long term, but it rises very quickly during the financial crisis and fluctuates afterwards. It might be the reason that although financial crisis made the rich earn less, but it made the economic condition worse, thus the poor is suffering more from the bad economic environment.

(a) Top 1\% income share vs. Gini coefficient of equivalized household income

Income share (\%)

Gini coefficient $(\%)$

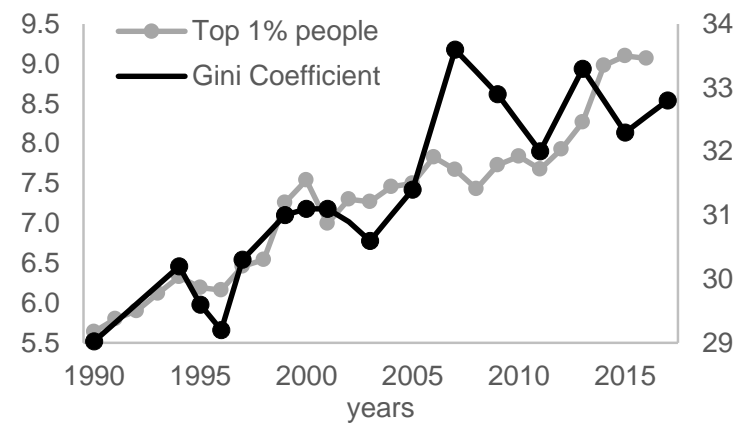

(b) Top 1\% income share vs. Top 10\% income share Top $1 \%$ people income Top $10 \%$ people income

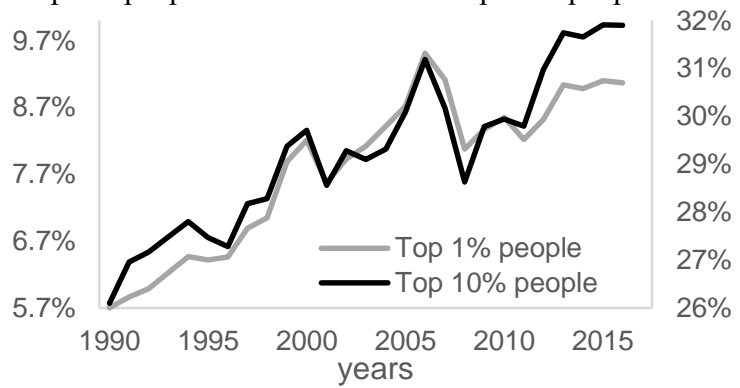

Figure 6. Income inequality in Australia has been risen in a fast pace, top income share indicator has large fluctuation in recent decade

Source: Chartbook of Economics Inequality for years 19902013 as available at 8/5/2020 [12];

The World Wealth and Income Database for years 19902017 as available at 8/5/2020;

Australian Bureau of Statistics: Household Income and Wealth (cat. no. 6523.0). as available at 10/5/2020 [13]

(a) Equivalized disposable household income is calculated 
by adjusting disposable income by the application of an equivalence scale.

(b) The Gini coefficient here values range between 0 and 100 (\%). Values closer to $0 \%$ represent higher equality and values closer to $100 \%$ represent higher inequality

Alongside with the rise in income inequality, wealth inequality is also increasing in Australia. The data to observe wealth inequality comes from survey data, so the data point is not as comprehensive as the income one. However, the upward trending in wealth inequality is obvious in recent decades. The wealth distribution would be even more shocking than the income one, the bottom $20 \%$ of people will only retain not even $1 \%$ of total share of wealth, and it is still decreasing, whereas the rich is getting even richer. The uneven distribution of wealth could lead to more aggressive income inequality, as people can make more income from a larger wealth basis.

The consumption has relatively more even distribution compared to income's and wealth's. The higher household income or household wealth group tends to consume more. Overtime, the highest income group has grown the consumption much faster than the low-income group, it is slightly better under the wealth perspective, but the growth in consumption is still higher in higher net worth. As the end of quantile value become extreme, the inequality will become bigger issue.

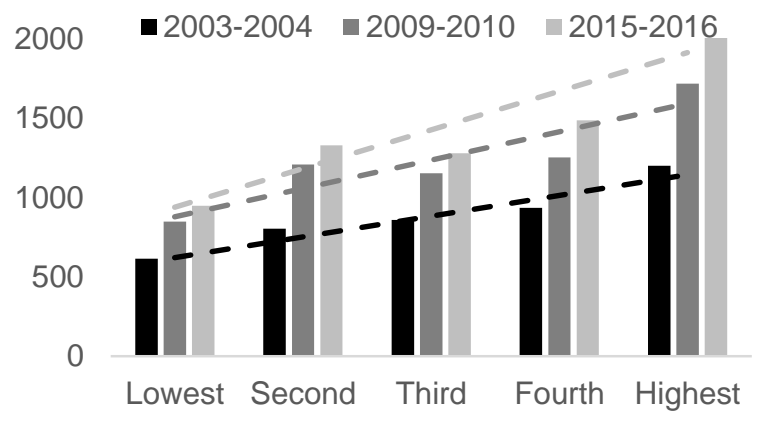

Household net worth quantiles

Figure 7. Wealth inequality in Australia has been increasing with some fluctuations

Source: Australian Bureau of Statistics: Household Expenditure Survey, Australia: Summary of Results for years 03-04, 09-10 and 15-16 (cat. no. 6530.0). as available at 10/5/2020

(a) The dash line showing the slope from lowest quantile to highest quantile, if the slope of trend line does not change, indicator the level of inequality does not change.

(a) Top 1\% wealth share vs. Gini coefficient of equivalized wealth

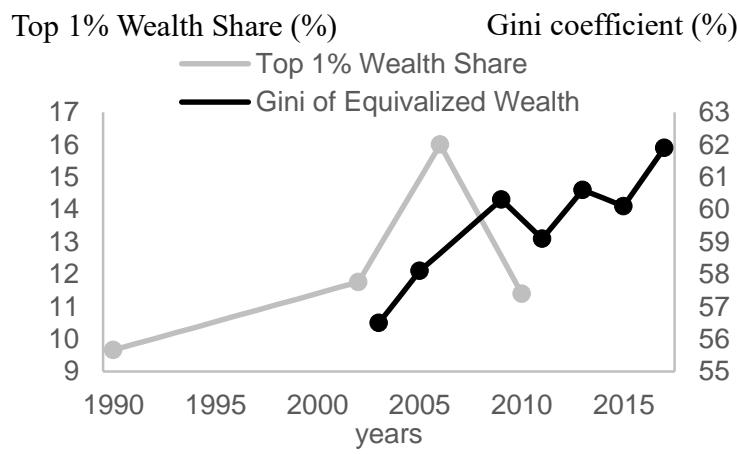

(b) Top $1 \%$ income share vs. Top $10 \%$ income share

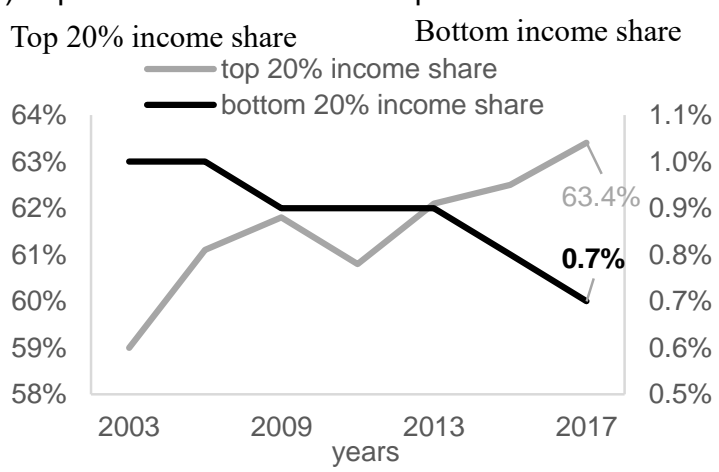

Figure 8. Wealth inequality in Australia has been increasing with some fluctuations 
Source: Chartbook of Economics Inequality for years 19902013 as available at 8/5/2020;

Australian Bureau of Statistics: Income, wealth and housing data are from the 2017-18 Survey of Income and Housing (cat. no. 6523.0). as available at 9/5/2020

(a) Equivalized wealth is calculated by adjusting personal wealth by the application of an equivalence scale.

(b) The Gini coefficient here values range between 0 and 100 (\%). Values closer to $0 \%$ represent higher equality and values closer to $100 \%$ represent higher inequality

The result in this report is supported by other findings about inequality in Australia. Productivity Commission report (2018) states that the income inequality has increased modestly and consumption inequality is increasing at a slower pace than income inequality. The wealth distribution is more uneven than income and consumption ones, but the household wealth distribution is more even in Australia compared to some other OECD countries. Another important finding in this area is from Kaplan, La Cava and Stone (2018) [14], they point out that some inequality trend shift has been persistent and propose that by including the imputed rent in income and wealth would imply a lower inequality in Australia.

\subsection{Impact Of Tax System And Economic Mobility}

The tax system in Australia and other countries in the world has effectively reducing the income inequality. As shown in Figure 9, as long as the taxation impact being include in income, the Gini coefficients, which indicates the inequality, will be reduced. The amount of reduction in inequality has been very different across countries, it might be some countries has more inequality than other, and it could also result from a more or less efficient tax system, and people's believe towards tax. Australia's tax system has being relatively effective in reducing inequality compared to those of other countries. In next Chapter, an optimal top income tax rate will be discussed for Australia.

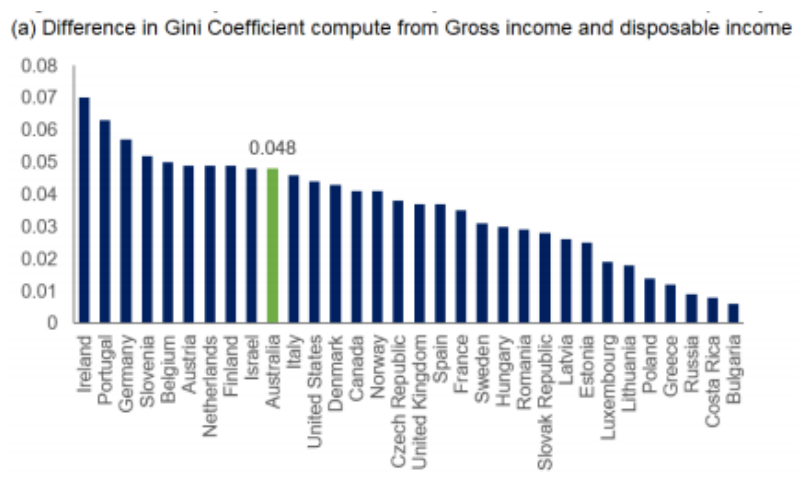

(b) Lorenz Curve compare the post-tax curve and pre-tax curve

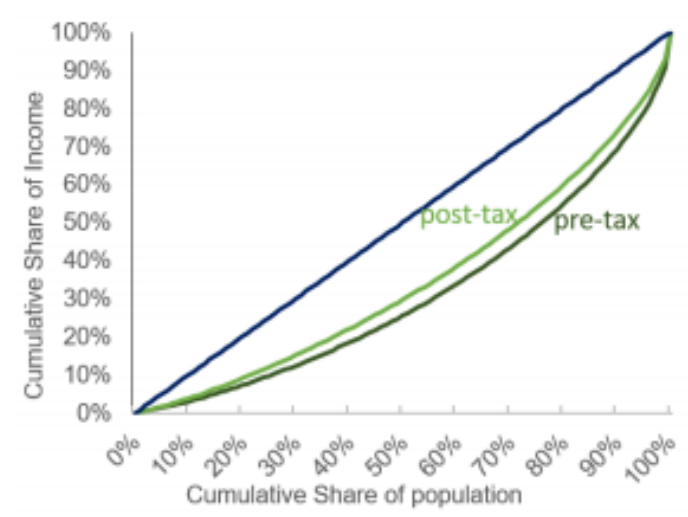

Figure 9 Tax system has effectively reduce the income inequality across country and in Australia

Source: OECD Income Distribution Database for year 2016 as avaiable at 8/5/2020; ATO Taxation Statistics 2016-17 Table 16: Individuals

Economic mobility is based on two board categories, impacts from life cycle and from parents. Deutscher (2018) [15] finds that in Australia parents moving to a place with better labour market condition can improve children's income, although the intergeneration mobility varies less through geographic in Australia than in US. Australia also has a favourable income mobility compared to many other developed countries such as UK and USA and ranked in the middle of developed countries for intergenerational mobility (Productivity Commission, 2018). Tax system can also have an impact towards wealth mobility through bequest behaviour, but this part of tax system is not the focus in this report.

\section{TAX POLICY}

Global income inequality does have a significantly upward trend from 1990 to 2017. Australia remains relative low level of income inequality compared to other selected countries, but inequality level rises overtime. The tax system is one of important tools to finance government expenditure and has a significant effect in reducing income inequality. An optimal tax policy can benefit national social welfare though the redistribution of economic resource.

\subsection{Optimal Labour Income Taxation Theory (Diamond And Zaez'11)[16]}

Optimal income taxation theory is a model that efficient distribution of tax burden across individual with different income. Models in optimal tax theory typically posit that the tax system should maximize a social welfare function subject to a government budget constraint, taking into account how individuals respond to taxes and transfers (Piketty,T,and S, 2014) [17]. The national social welfare becomes larger when economics resource distributed equality but redistribute taxes can have a 
negatively effect to work and earn income. Therefore, there should be an optimal point to balance mechanical tax increase and behavioural tax loss. The optimal top income tax rate can be illustrated as a graph:

Where $\mathrm{z}$ is individual earning and $\mathrm{T}$ is tax ratio (Diamond and zaez'11).

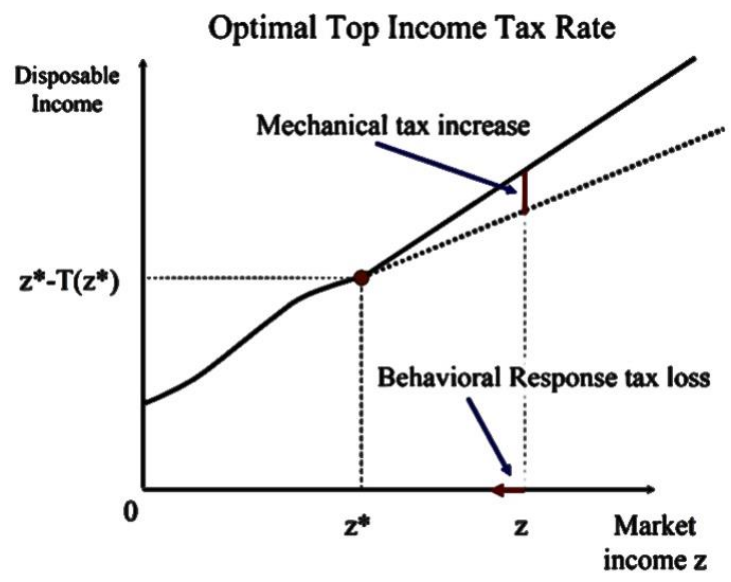

Source: Dlamond and Saez JEP'11

Figure 10 Optimal Top Income Tax Rate

Let $z_{m}$ be average income for people with $z \geq z^{*}$, and $z^{*}$ is the minimum income level for the income group. Then mechanical increase in tax revenue is $\Delta \mathrm{M}=$ $N^{*} \cdot\left[z_{m}-z^{*}\right] \Delta T$ and Behavioral response reduces tax revenue is $\Delta \mathrm{B}=N^{*} \cdot T \cdot \Delta z_{m}$. The optimal tax rate $\mathrm{T}$ should combine mechanical tax increase and Behavioral tax loss to be zero, the function of these two combinations can be show as:

$$
\begin{gathered}
\Delta \mathrm{M}+\Delta \mathrm{B}=\Delta T \quad N^{*} \cdot\left[\left(z_{m}-z^{*}-e \frac{\mathcal{T}}{1-\mathcal{T}} z_{m}\right)\right] \Delta T \\
\frac{\mathcal{T}}{1-\mathcal{T}}=\frac{\left(z_{m}-z^{*}\right)}{e \cdot z_{m}} \\
\mathcal{T}=\frac{1}{1+a e} \quad \text { with } a=\frac{z_{m}}{\left(z_{m}-z^{*}\right)}, e=\left(\frac{1-\mathcal{T}}{z_{m}} \frac{\Delta z_{m}}{\Delta(1-\mathcal{T})}\right)
\end{gathered}
$$

There are three factors to determine optimal taxation rate. Firstly, the letter $e$ represents the elasticity of $z_{m}$ with respect to $1-\mathcal{T}$, it is important factor that measure people response to changes of tax rate. Optimal tax rate $\mathcal{T}$ will be less when elasticity (e) of $z_{m}$ respect to $1-$ $\mathcal{T}$ is high, one possible explanation is that people are less sensitive to tax rate changes and government will be able to charge a higher rate without having too much people transfer to other income group. Behavioural response is difficult to measure but has large effect on optimal tax rate. Secondly, the letter $a$ represents thinness of top tail of income distribution, it is an alternative way to measure inequality. The large value of $a$ would imply more equality, because the average top income is closer to the average income of people. Therefore, optimal tax rate will decrease if $a$ has larger value. Thirdly, Social welfare weight on top earner also affects the optimal top tax rate, but it is hard to measure society's preferences.

\subsection{Optimal Top Income Tax In Australia}

The range of first level of individual taxable income in Australia is 180,001 dollar per year and need to pay tax with $45 \%$ tax rate. Based on data from ATO taxation statistic 2016-17 individuals, top 4\% income group is target by this range. The share of top income group sustains a growth over time, but top income tax rate remains unchanged. Therefore, it is necessary to estimate an optimal top tax rate with recent data.

Let $z^{*}$ be the lower bund of top $4 \%$ income group (\$181,025 in 2016), and $z_{m}$ be average income of top $4 \%$ income group ( $\$ 347,753$ in 2016). The value of $a$ that thinness of top tail of income distribution is

$$
a=\frac{z_{m}}{\left(z_{m}-z^{*}\right)}=\frac{347,753}{(347,753-181,025)}=2.086 .
$$

There are huge literatures estimating the behaviour responses, however, it is difficult to find one estimating the e in Australia. There is one recent review about $e$ in US made by Slemrod, Saez and Giertz (2012) [18], they conclude that $e$ lies somewhere in the rage of 0.25 to 0.5 . The elasticity should be different in different countries due to the political environment, different target top income group, cultural background, and other complimentary policy to the tax system. With reference to the study made by Slemrod, Saez and Giertz (2012), the optimal top income tax rate in Australia will show a linear relationship to the suggested elasticity range, with Figure 11 showing the optimal taxation rate for target income group respect to behaviour response e:

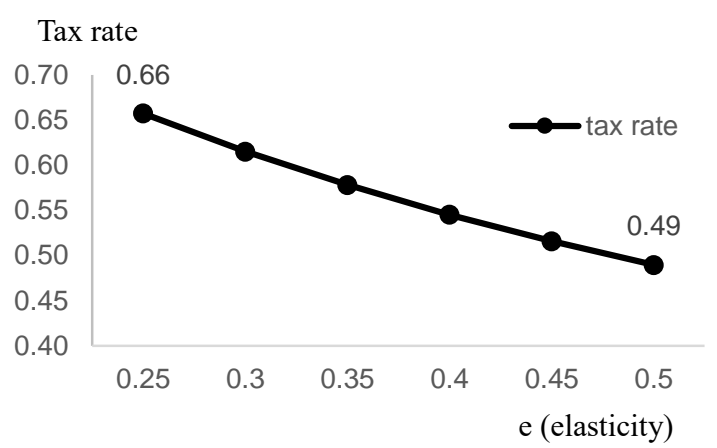

Figure 11. The optimal tax rate for target top income group falls within the range of 0.49 to 0.66

Source: The statistic is calculated based on ATO statistic 2016 2017 table 16

(a) $e$ is the elasticity of people earn more than \$181,025 income towards tax rate

(b) The optimal tax rate is determined by formula $t=1 /\left(1+e^{*} a\right)$, here a is the thickness of top income group in the distribution (c) Income group is determined based on ATO 2016-2017 tax income information, a based on this information is 2.086

The results provide an optimal taxation rate of top $4 \%$ income group as the range of 0.49 to 0.66 . The lowest optimal taxation rate is 0.49 respect to elasticity as 0.5 , it is higher than current top tax rate as 0.45 . Based on range of e provide by Slemrod, Saez and Giertz (2012), from 
previous section, Australia income inequality has a much lower level than the income inequality in US, it is very likely that Australia behavior response e will be lower than 0.5. It implies that government will still has space to increase taxation on highest income level taxpayer to reduce economics inequality.

The key uncertainty in optimal taxation model is behaviour response to tax changes. In figure 11, a small change in e lead to big difference in optimal tax rate. A limitation of measuring behavioural responses is that many important margins of behaviour cannot be adjusted in short run, such as career choice and level of education. In general, long-run e likely larger than short run e. It represents optimal taxation rate in long run smaller than taxation rate in short run, but it is difficult to find a convincing evident to measure long run e.

Although Australia has a more evenly distributed wealth compared to other countries (Productivity Commission, 2018), wealth inequality greater than income inequality all the period across all countries. People's income can be made from both income and wealth, but it is hard to distinguish between labour income and capital income. If return on wealth is higher than return than labour income, business owners and employees doing evasive jobs will shift labour income into wealth income. It implies the business owners, very likely a representative group of top income earners, will have their own ways to avoid tax if the according tax rate is high. One important way to develop capital taxation is by taxing inheritance tax, which Australia does not have now.

\section{IMPLICATION OF THE ALTERNATIVE TAX RATE}

Based on analysis of optimal taxation theory, Australia government has a significantly policy space that increases tax rate to reduce inequality. It means counties with higher education have a lower intergenerational mobility. Figure 12 shows the growth of education spending is mainly driven by the increasing investment from private source, and the government expenditure in education is not growth as fast as private source.

(a) Private and government annual expenditure on education (\% GDP)

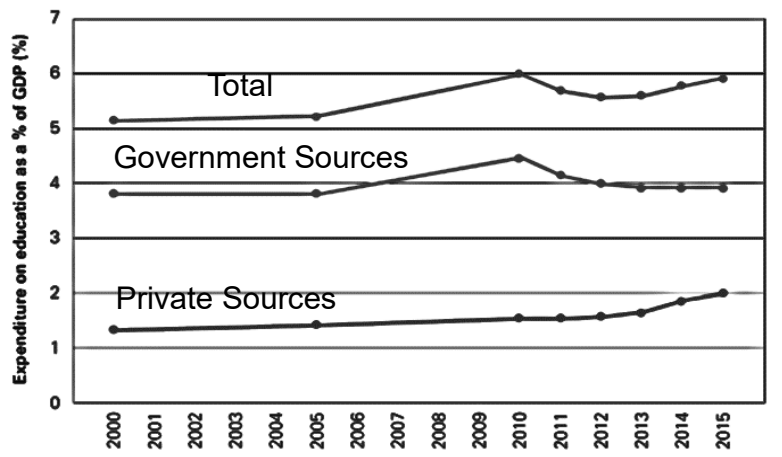

(b) Private and government annual expenditure on education

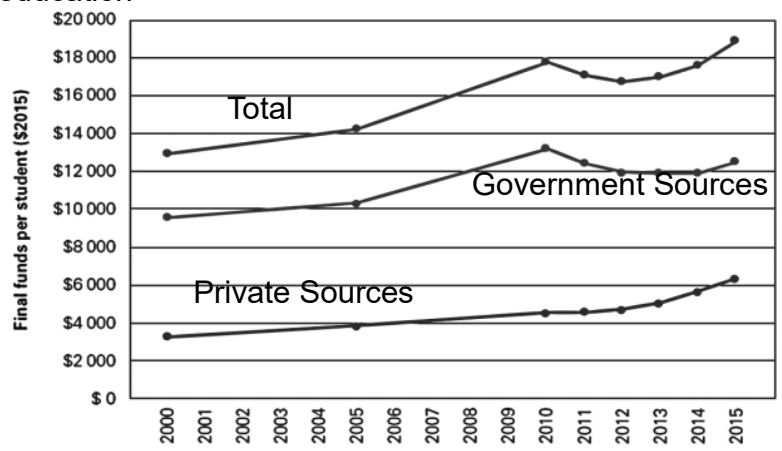

Figure 12. Australia overall education spending as proportion of revenue has increased, due to personal increasing investment in education. Government spending in education increase, while proportion slightly decrease

Source: Australian Council for Educational Research Education Expenditure in Australia [19]

\section{CONCLUSION}

Inequality in Australia maintains a relatively low level compared to OECD countries and other countries in the world. The average income, wealth and consumption levels increase over time, but the inequality from these measurements also rise, and the increments of income inequality is most obvious compare to other perspectives.

The optimal taxation theory is utilized to find the range of optimal tax rate in Australia. It is difficult to determine the behaviour response e respect to tax changes in Australia based on current research scope, but in the light of a study made in US (Slemrod, Saez and Giertz, 2012), the behaviour response ranges from 0.25 to 0.5 is used for calculation. The optimal tax rate based on Australian data above e range should lie somewhere between 0.49 and 0.66 . Australia optimal tax rate should be at least higher than the lower bound (0.49) of previous range, because inequality level in Australia is lower than that in US. Therefore, it reasonable to conclude that the current tax rate for top $4 \%$ income group in Australia is much lower than potential optimal tax rate, it implies that Australia will still be able to reduce income inequality by raising the top income tax. 
Furthermore, the reason of Australia with high education has low intergenerational mobility is that educational attainment is highly persistent with parental education and earnings. The high-income and wealthy people are expected to have more inputs in education, by attaining a higher degree or learning beyond school. Children with more educational investment will be better off when return of skill is positive. The increase of government expenditure in the education system will benefit the poor more than the rich, and thus reduce inequality.

\section{REFERENCES}

[1] Leigh, A. (2017). Why corporate Australia should care about inequality. Business Insider Australia. Retrieved May $\quad 6^{\text {th }} \quad 2020$ from https:/www.businessinsider.com.au/whycorporate-australiashould-\%20care-aboutinequality-2017-3

[2] Carling, R. (2017). Whatever happened to incentive? Centre for Independent Studies. Retrieved May $6^{\text {th }}$ 2020 from

http://www.cis.org.au/commentary/articles/whateve r-happened-to-incentive/

[3] The World Wealth and Income Database. (n.d.). Australia. Retrieved May $6^{\text {th }} 2020$ from https://wid.world/country/australi

[4] Index Mundi. (2020). GINI index (World Bank estimate) - Country Ranking. Retrieved May $5^{\text {th }}$ 2020 from

https://www.indexmundi.com/facts/indicators/SI.P OV.GINI/rankings

[5] OECD Income Distribution Database. (2020). OECD Income Distribution Database (IDD): Gini, poverty, income, Methods and Concepts. Retrieved May $6^{\text {th }}$ 2020 from https:/www.oecd.org/social/incomedistribution-database.htm

[6] Australia Taxation Office. (2019). Taxation Statistics 2016-17, Individuals - Table 16. Retrieved May $6^{\text {th }}$ 2020 from https:/data.gov.au/data/dataset/taxationstatistics-2016-17/resource/8553eb2d-9de5-4a57ad9d-6e52933287b2

[7] Productivity Commission. (2018). Rising inequality? A stocktake of the evidence. Commission Research Paper. Canberra.

[8] Kuziemko, Ilyana, Michael Norton, Emmanuel Saez, and Stefanie Stantcheva. (2015).How Elasticare Preferences for Redistribution: Evidence from Randomized Survey Experiments. American Economic Review 105(4):1478-1508

[9] Australian Bureau of Statistics. (2005). Household Expenditure Survey, Australia: Summary of Results,
2003-2004 (Cat. no. 6530.0). Canberra, Australia: ABS.

[10] Australian Bureau of Statistics. (2011). Household Expenditure Survey, Australia: Summary of Results, 2009-2010 (Cat. no. 6530.0). Canberra, Australia: ABS.

[11] Australian Bureau of Statistics. (2017). Household Expenditure Survey, Australia: Summary of Results, 2015-2016 (Cat. no. 6530.0). Canberra, Australia: ABS.

[12] Chartbook of Economics Inequality. (2017). Economics Inequality in Australia Database. Retrieved May $\quad 6^{\text {th }} \quad 2020$ from https://www.chartbookofeconomicinequality.com/i nequality-by-country/australia/

[13] Australian Bureau of Statistics. (2019). Household Income and Wealth, Australia, 2017-2018 (Cat. no. 6523.0). Canberra, Australia: ABS.

[14] Kaplan, G., La Cava, G., \& Stone, T. (2018). Household economic inequality in Australia. Economic Record, 94(305), 117-134.

[15] Deutscher, N. (2018). Place, jobs, peers and the importance of the teenage years: exposure effects and intergenerational mobility.

[16] Diamond, P., \& Saez, E. (2011). The case for a progressive tax: from basic research to policy recommendations. Journal of Economic Perspectives, 25(4), 165-90.

[17] Piketty, T., Saez, E., \& Stantcheva, S. (2014). Optimal taxation of top labor incomes: A tale of three elasticities. American economic journal: economic policy, 6(1), 230-71.

[18] Saez, E., Slemrod, J., \& Giertz, S. H. (2012). The elasticity of taxable income with respect to marginal tax rates: A critical review. Journal of economic literature, 50(1), 3-50.

[19] Rice, J.M., Edwards, D., \& McMillan, J. (2019). Education Expenditure in Australia. Australian Council for Educational Research. Retrieved 13 May 2020, from https://research.acer.edu.au/cgi/viewcontent.cgi?art icle $=1029 \&$ context $=$ policy_analysis_misc 